\title{
Indirect and Subliminal "Mere Exposure" Effect: Implicit Aspect of Attitude Formation
}

\section{P. Chambres, D. Bonin and K. Grenier}

\section{(2) OpenEdition \\ 1 Journals}

\section{Electronic version}

URL: http://journals.openedition.org/cpl/179

DOI: $10.4000 / \mathrm{cpl} .179$

ISSN: $1379-6100$

\section{Publisher}

Centre PsyCLÉ

\section{Printed version}

Date of publication: 1 April 2001

\section{Electronic reference}

P. Chambres, D. Bonin and K. Grenier, «Indirect and Subliminal "Mere Exposure" Effect: Implicit Aspect of Attitude Formation », Current psychology letters [Online], 2001/1, 4 | 2001, Online since 05 September 2003, connection on 08 September 2020. URL : http://journals.openedition.org/cpl/179 ; DOI : https://doi.org/10.4000/cpl.179

This text was automatically generated on 8 September 2020.

(C) All rights reserved 


\section{Indirect and Subliminal "Mere Exposure" Effect: Implicit Aspect of Attitude Formation}

P. Chambres, D. Bonin and K. Grenier 